\title{
Tow-Objective Model of Green Supply Chain with the Cost Evaluation
}

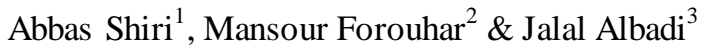 \\ ${ }^{1}$ Student of electrical engineering, Islamic Azad University Gachsaran, Iran \\ ${ }^{2}$ Postgraduate Student of Industrial Engineering, Gachsaran Branch, Islamic Azad University Gachsaran, Iran \\ ${ }^{3}$ Lecturer of chemistry, Islamic Azad University Behbahan, Iran \\ Correspondence: Mansour Forouhar, Postgraduate Student of Industrial Engineering, Gachsaran Branch, Islamic \\ Azad University Gachsaran, Iran. Tel: 989377424301.E-mail: forouhar_tak@yahoo.com
}

Received: January 15, 2017

doi:10.5539/mas.v11n6p29
Accepted: February 16, 2017 Online Published: April 23, 2017

URL: https://doi.org/10.5539/mas.v11n6p29

\begin{abstract}
In recent years, the supply chain has become a subject of interest for the managers and captains of industry and the life and death of the business organizations and corporation depend on the activity of intertwined chains. Beyond this definition, by adding the term Green, chain management refers to green procurement, green production, green distribution, green supply and inverse logistic. The main approach of this paper is designing and offering a mathematical model for designing the green supply chain networks, which three-level planning is developed, which is aimed in optimizing two contradictory goals and has problem conflicts including 1minimization of costs, and 2- minimization of environmental pollutants. The problem is expressed as the longitudinal programming of integer numbers. Results show applicability and practicality of this model.
\end{abstract}

Keywords: model, green supply chain, multi-objective, optimization, evaluation cost

\section{Introduction}

Much attention has been paid to environmental effects over two recent decades and these effects are considered along with traditional indexes in designating supply change (Lee \& Billington, 1992). Green supply chain management (GSCM) has been considered as a novel management concept in recent of environmental damages over recent decades such as loss of non-renewable resources, saturation of waste collection sites and increased amount of environmental pollutants (Fung \& Chen, 2004).

Many aspects of supply chain can be improved through GSCM. Studies conducted on life cycle analysis show that over seventy percent of available opportunities for reduction of environmental effects and reducing the needs for resources are specified by the product design (Manzini, Gamberi, Gebennini, \& Regattieri, 2008).

The issue of supply chain at the current world is considered as a main competitive advantage in way of decreasing final price (Donald \& Waters, 2003). Supply chain includes purchasing and supply, logistics and shipping, marketing, organizational behavior, networking, strategic management, management information systems and operations management (Chen \& Paulraj, 2004). However, decision making in different steps of the process and matching with these steps is the main challenge of supply chain. According to intense competition among suppliers, if each ring of this chain acts weakly, whole system would be failed and would not act in expected level. Therefore, effective management of the chain in industry is a main management challenge (Handfield \& Nichols, 1999). Over the years, companies and organizations of industrial and developed countries of the world have paid specific attention to supply chain management and have achieved considerable successes through this. The evidence for this issue is high volume of commercial transactions and profitability and income of successful and efficient supply chain, which has been able to overtake of competitors at the current highly competitive markets (Donald \& Waters, 2003).

Green design concepts have been broadly used in GSCM area for designing products with special environmental considerations. (Srinivas \& Rao, 2010; Min \& Zhoub, 2002). Some studies have been done in relation with designing green supply chain in the reviewed literature (Paksoy \& Pehlivan et al. 2012). Proposed a fuzzy multi-objective model for designing green supply chain network in risky conditions and environmental risks. In addition (Dullaert, Braysy, Goetschalckx \& Rua, 2007; Feredendall \& Hill, 2000; (Jamshidi, FatemiGhomi et al. 
2012).Optimized a multi-objective green supply chain with a new hybrid memetic algorithm using the Taguchi method (Paksoy \& Pehlivan et al. 2012).

accordingly, the current study is aimed at providing an integrated model so that first, at the level of the previous (suppliers) links and next (distribution centers) links, it can select as green, and then it moves toward green production by optimizing production culture and using mechanisms of waste collection and recycling them to the production cycle at the operational level. Using this method, supply chain process integration theory and specifically green chain can be practically implemented.

\section{Literature Review}

Today, systematic approach and issues of supply chain are being considered as known subjects in industrial engineering. High volume and variety of studies in field of supply chain management indicate importance and interestingness of this issue.

Handfield and Nichols (Handfield \& Nichols, 1999) believe that 3 main factors have made companies follow issue of supply chain seriously as follows:

1- Information revolution

2- Increase in expectations of customers while purchasing products

3- Necessity of creating a new structure in inter-organization relations.

In this study, the problem of integrated planning of Purchase-production-customer in supply chain is modeled and solved. As it is obvious in figure 1, assumed supply chain has 3 levels and in levels 1 to 3, suppliers, manufacturers and customers are respectively placed. Two contradictory goals of this issue include 1minimization of costs, 3- minimization of environmental pollutants.

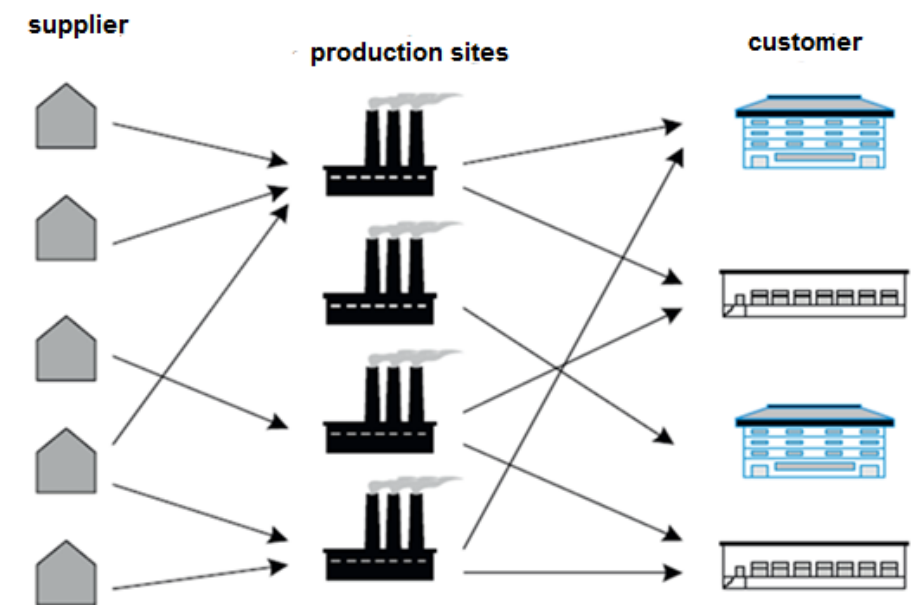

Figure 1. A network of three-stage supply chain

The problem solving should specify that how much raw materials from which supplier should be received in each period; in which production unit and with what level of human resource would be involved to produce finally a product to minimize supply chain costs to gain customer satisfaction. You should also make sure that the entire supply chain environmental impact of the supply chain to the lowest possible level is reached (Beamon, 1998; Lambert \& Cooper, 1998).

\section{Methodology}

Conditions of the problem:

- $\quad$ The problem is a single-product, multi-period and three-layer model.

- $\quad$ Place and number of suppliers, manufacturers, distribution centers and retail centers are specified.

- $\quad$ The flow of materials can be provided just between two sequential levels of network layers. 
- $\quad$ Capacity of each facility (supplier) and access time of each level of human resource is specified.

- $\quad$ Parameters have been considered definitely.

In way of designing the network, 2-objective and 3-layer supply chain is formed as a result of outputs including:

- $\quad$ Selecting suppliers

- $\quad$ Selecting manufacturers

- Optimal purchase of types of raw materials and optimal use of labor involved in each period and to determine optimal type of production, determine optimal method of shipping of raw materials to the factory and transiting products and delivering them to customers

- An optimization approach with the goal of minimization of supply chain costs.

- An optimization procedure with the aim of minimizing environmental pollutants

As it is clear from nature of considered goals, two considered goals are in contradiction. Hence, improvement of one of them may lead to weakness of another one and it is almost impossible to find an answer to optimize two target functions at the same time. As a result, balanced solutions to goals should be found. One of the methods to obtain Pareto solutions is using multi-objective meta-heuristic methods, which produce more Pareto solutions in reasonable time compared to classic algorithms. Hence, Non-dominated Sorting Genetic Algorithm-II (NSGA-II) is designed and implemented to obtain set of optimized Pareto solutions to the proposed model (Vaziri \& Shojaei, 2011).

\section{Presenting Mathematical Model}

In order to present mathematical model of the problem, firstly hypotheses are remembered:

- $\quad$ The problem is a single-product, multi-period and three-layer model.

- $\quad$ Place and number of suppliers, manufacturers and customers are specified.

- Level of equipment in manufacturing centers is considered same.

- Human resources with skill of level 1 are professional resources and human resources in $\mathrm{K}$ level are trainees.

- It has been specified by experts and based on previous experiences that product of q degree could be produced with what extent of human resource and with what level of materials.

\subsection{Sets}

S: set of supplier's $s=1,2 \ldots S$

L: quality level of raw materials $\mathrm{l}=1,2 \ldots \mathrm{L}$

$\mathrm{K}$ : skill level of human resources $\mathrm{K}=1,2 \ldots \mathrm{K}$

q: quality level of final product $\mathrm{q}=1,2 \ldots \mathrm{q}$

C: set of customers/retailors $C=1,2 \ldots C$

$\mathrm{J}$ : set of manufacturers $\mathrm{j}=1,2 \ldots \mathrm{J}$

T: time period $\mathrm{t}=1,2 \ldots \mathrm{T}$

\subsection{Parameters}

- $D_{\text {ct }}$ : customer demand during t period

- $\quad \boldsymbol{C}_{\mathbf{s}}^{\boldsymbol{l}}$ : purchase cost of a unit of raw materials from s supplier

- $\quad \boldsymbol{T} \boldsymbol{c}_{\boldsymbol{s} j}$ : shipping cost of raw materials from supplier s to manufacturer j per unit

- $\quad \mathbf{T c}_{\mathbf{j c}}$ : shipping cost of product from manufacturer $\mathrm{j}$ to customer c per unit

- $\quad \boldsymbol{M} \boldsymbol{w}_{\boldsymbol{k j t}}$ : cost of operator with k level skill during t period in j factory

- $\quad \boldsymbol{F} \boldsymbol{w}_{\boldsymbol{k j t}}$ : cost of firing $\mathrm{K}$ level operator from j factory during t period

- $\mathrm{Hw}_{\mathrm{kjt}}$ : cost for employment of operator with $\mathrm{k}$ skill level in $\mathrm{j}$ factory during t period

- $\quad \mathbf{T w}_{\mathbf{k k} / j \mathbf{j}}$ : training cost of operator from k skill level to K' skill level in $\mathrm{j}$ factory during t period 


\section{- $\quad \boldsymbol{T}_{\boldsymbol{k}_{\boldsymbol{k}} \boldsymbol{k}^{\prime}}:\left\{\begin{array}{c}\text { 1:if training is possible from } k \text { skill level to } k^{\prime} \text { skill level } \\ \text { 0: otherwise }\end{array}\right.$}

- $\quad \boldsymbol{A}_{\boldsymbol{k j \mathrm { t }}}$ : time of access to j factory for operator of k level during t period

- $\quad \boldsymbol{a}_{\mathbf{j} \mathbf{t}}^{\mathbf{k l}}$ : number of required labor of $\mathrm{k}$ level in case of working on materials of 1 level to produce product in $\mathrm{j}$ factory during t period

- $\quad \boldsymbol{i} \boldsymbol{c}_{\boldsymbol{j}}$ : maintenance cost of a unit of product in $\mathrm{j}$ factory

- $\quad \boldsymbol{C a p}_{s t}^{l}$ : maximum capacity of providing raw materials of type l supplied by s supplier during t period

- M: large number

- $\quad: \boldsymbol{b}_{\boldsymbol{j l k}}$ : production time of a unit of product in $\mathrm{j}$ factory by operator of $\mathrm{k}$ level and law materials of 1 level

4.3 Variables

- $\quad \boldsymbol{X}_{s j t}^{L}$ : amount of raw materials with 1 level quality transferred from s supplier to $\mathrm{j}$ manufacturer during $\mathrm{t}$ period

- $\quad \boldsymbol{X}_{\boldsymbol{j} \boldsymbol{t}}^{\boldsymbol{l}}$ : amount of product produced with skill level of $\mathrm{k}$ and raw materials of $\mathrm{l}$ level in $\mathrm{j}$ factory during $\mathrm{t}$ period

- $\quad \boldsymbol{Y}_{\boldsymbol{j} \boldsymbol{} \boldsymbol{t}}$ : amount of product transferred from manufacturer j to c customer during t period

- $\boldsymbol{I}_{\boldsymbol{j} \boldsymbol{t}}$ : amount of inventory of product in $\mathrm{j}$ factory during t period with quality of q level

- $\quad \mathbf{L}_{\mathbf{k j t}}$ : number of required human resources from $\mathrm{k}$ skill level in $\mathrm{j}$ factory during t period

- $\quad \boldsymbol{F}_{\boldsymbol{k j \boldsymbol { t }}}$ : number of human resource with skill level of $\mathrm{k}$ in $\mathrm{j}$ factory during $\mathrm{t}$ period, who are fired

- $\quad \boldsymbol{H}_{\mathbf{k j t}}$ : number of human resources with $\mathrm{k}$ skill level in $\mathrm{j}$ factory during t period, who are employed

- $\quad \boldsymbol{T} \boldsymbol{l}_{\boldsymbol{k} \boldsymbol{k}^{\prime} \boldsymbol{j} \boldsymbol{t}}$ : number of human resources with $\mathrm{k}$ skill level to $\mathrm{K}$ ' level trained in $\mathrm{j}$ factory during t period

- $\boldsymbol{e}_{\boldsymbol{p}}^{\boldsymbol{p r o}}$ : Environmental impact of a unit of product $\mathrm{p}$

- $\boldsymbol{e}_{\boldsymbol{i j p}}^{\boldsymbol{p d}}$ : Environmental impact of carry a unit of product p from the place i to $\mathrm{j}$

- $\quad \boldsymbol{e} \boldsymbol{i}_{\boldsymbol{j} \boldsymbol{k} \boldsymbol{p}}^{\boldsymbol{d} \boldsymbol{c}}$ : Environmental impact of carry a unit of product $\mathrm{p}$ from the place $\mathrm{j}$ to $\mathrm{k}$

- $\quad \boldsymbol{e i}_{\boldsymbol{j} \boldsymbol{i p}}^{\boldsymbol{i p}}$ : Environmental impact of carry a unit of product p from the place $\mathrm{j}$ to I

- $\quad \boldsymbol{e i}_{\boldsymbol{j} \boldsymbol{i m p}}^{\boldsymbol{i d}}$ : Environmental impact of carry a unit of product $\mathrm{p}$ from the place $\mathrm{j}$ to $\mathrm{m}$

- $\quad \boldsymbol{e i}_{\boldsymbol{j} \boldsymbol{p}}^{\boldsymbol{i n}}$ : Environmental impact inspection of a unit of product $\mathrm{p}$ in the place $\mathrm{j}$

- $\quad \boldsymbol{e} \boldsymbol{i}_{\boldsymbol{i} \boldsymbol{p}}^{\boldsymbol{r} \boldsymbol{e}}$ : Environmental impact of recycling a unit of product in the place i

- $\boldsymbol{e} \boldsymbol{i}_{\boldsymbol{m} \boldsymbol{p}}^{\boldsymbol{d i}}$ : Environmental impact excretion of a unit of product in the place $\mathrm{m}$

\subsection{Target Functions of Problem}

\subsubsection{First Target Function}

Minimization of costs $=$ Raw materials purchase cost + Raw materials shipping costs + production cost + shipping product to the customer + inventory costs + labor costs + cost of hiring human resources + cost of firing human resources + cost of human resource training

$\operatorname{Min} Z_{1}=$

$$
\begin{array}{r}
\sum_{s} \sum_{j} \sum_{l} \sum_{t} X_{s j t}^{l} C_{s}^{l}+\sum_{s} \sum_{j} \sum_{l} \sum_{t} T c_{s j} X_{s j t}^{l}+\sum_{j} \sum_{c} \sum_{t} T c_{j c} Y_{j c t}+\sum_{j} \sum_{t} i c_{j} I_{j t}+\sum_{k} \sum_{j} \sum_{t} M w_{k j} L_{k j t}+ \\
\sum_{k} \sum_{j} \sum_{t} F w_{k j} F l_{k j t}+\sum_{k} \sum_{j} \sum_{t} H w_{k j} H l_{k j t}+\sum_{k} \sum_{k \prime} \sum_{j} \sum_{t} T w_{k j} T l_{k k^{\prime} j t}
\end{array}
$$

\subsubsection{Second Target Function}

$$
\begin{aligned}
& M i n Z_{2}=\sum_{i, j, p}\left(e i_{i j p}^{p d}+e i_{i p}^{p r o}\right) x_{i j p}+\sum_{j, k, p}\left(e i_{j k p}^{d c}+e i_{j p}^{i n}\right) u_{j k p}+\sum_{i, j, p}\left(e i_{j i p}^{i p}+e i_{i p}^{r e}\right) v_{j i p}+\sum_{j, m, p}\left(e i_{j m p}^{i d}+\right. \\
& \left.e i_{m p}^{d i}\right) T_{j m p} \text { (2) } \\
& 4.5 \text { Model limitations }
\end{aligned}
$$

$$
\mathrm{I}_{\mathrm{jt}}=\mathrm{I}_{\mathrm{j}(\mathrm{t}-1)}-\sum_{\mathrm{C}} Y_{j c t} \forall \mathrm{c}, \mathrm{j}, \mathrm{t}
$$




$$
\begin{aligned}
& L_{k j t}=L_{k j(t-1)}+H l_{k j t}-F l_{k j t}+\sum_{k^{\prime}} T l_{k^{\prime} k j t}-\sum_{k^{\prime}} T l_{k k^{\prime} j t} \forall k, j, t(4) \\
& \sum_{L} \mathrm{a}_{\mathrm{jt}}^{\mathrm{kl}} \mathrm{x}_{\mathrm{jt}}^{\mathrm{kl}} \leq \mathrm{L}_{\mathrm{kjt}} \forall k, j, t \\
& \sum_{\mathrm{k}} A_{t k j} \mathrm{~L}_{\mathrm{tkj}} \geq \sum_{\mathrm{k}} \sum_{\mathrm{L}} \mathrm{b}_{\mathrm{jlk}} \mathrm{X}_{\mathrm{jt}}^{\mathrm{LK}} \forall j, t(6) \\
& \sum_{j} X_{s j t}^{L} \leq \operatorname{Cap}_{s t}^{L} \forall L, s, t \\
& \sum_{\mathrm{k}} \mathrm{X}_{\mathrm{jt}}^{\mathrm{kL}}=\sum_{\mathrm{s}} \mathrm{X}_{\mathrm{sjt}}^{\mathrm{L}} \forall \mathrm{L}, \mathrm{j}, \mathrm{t} \\
& \mathrm{FL}_{\mathrm{kjt}}+\sum_{\mathrm{k},} \mathrm{TL}_{\mathrm{kk}, j \mathrm{t}} \leq \mathrm{L}_{\mathrm{kj}(\mathrm{t}-1)} \forall k, j, t \\
& \mathrm{D}_{\mathrm{ct}}=\sum_{\mathrm{j}} \sum_{q} Y_{j c t} \forall c, t \\
& \sum_{\mathrm{k},} \mathrm{TL}_{\mathrm{kk} / \mathrm{jt}} \mathrm{FL}_{\mathrm{kjt}}=0 \forall k, j, t \\
& T l_{k^{\prime} k j t} \leq M T p_{k k^{\prime}} \forall k, k^{\prime}, j, t \\
& \sum_{k}\left(F L_{k j t}+H L_{k j t}\right) \leq \alpha_{(t-1)} \sum_{k} L_{k j(t-1)} \forall j, t \\
& X_{s j t}^{L}, X_{j t}^{l k}, Y_{j c t}, I_{j t}, L_{k j t}, F l_{k j t}, H l_{k j t}, T l_{k k^{\prime} j t} \geq 0
\end{aligned}
$$

Limitation 3: indicates inventory of each period, which is determined according to inventory of previous period and production and delivered products; limitation 4: indicates number of labors with $\mathrm{k}$ skill in each factory and during each period; limitation 5 guarantees number of required labor per each period due to. Limitation 6 guarantees considering time of accessibility of each labor. Limitation 7 guarantees that per each period, amount of semi-cast product received from suppliers should not be more than capacity of supplier. Limitation 8 indicates the balance between production and raw materials. Limitation 9 indicates that firing and training should not be more than in access human resources. Limitation 10 guarantees that all demands for product in each period should be provided. Limitation 11 guarantees that an operator trained in a period should not be fired by the same period. Limitation 12 indicates possibility or impossibility of training per each period. Limitation 13 indicates that in each period, human resources can be changed to certain level. Limitation 14 indicates nonnegative limitations of decision variables.

\subsection{Linearization of Nonlinear Function}

As in limitation 11, multiplication of 2 decision variables is possible, the presented model is nonlinear. In order to linearize the model, new variable that is 0 and 1 should be considered as follows:

$$
\begin{gathered}
\sum_{k^{\prime}} T L_{k k^{\prime} j t} \leq M Y_{k j t} \\
F L_{k j t} \leq M\left(1-Y_{k j t}\right) \\
Y_{k j t} \in\{0,1\}
\end{gathered}
$$

The limitation should be added to the model. In the equation, real number is large. 
Accordingly, Integer linear programming (ILP) model is obtained as follows:

$$
\begin{gathered}
\text { Min Z1 }=\sum_{s} \sum_{j} \sum_{l} \sum_{t} X_{s j t}^{l} C_{s}^{l}+\sum_{s} \sum_{j} \sum_{l} \sum_{t} T c_{s j} X_{s j t}^{l}+\sum_{j} \sum_{t} C_{j t}+\sum_{j} \sum_{c} \sum_{t} T c_{j c} Y_{j c t}+\sum_{j} \sum_{t} i c_{j} I_{j t}+ \\
\sum_{k} \sum_{j} \sum_{t} M w_{k j} L_{k j t}+\sum_{k} \sum_{j} \sum_{t} F w_{k j} F l_{k j t}+\sum_{k} \sum_{j} \sum_{t} H w_{k j} H l_{k j t}+\sum_{k} \sum_{k} \sum_{j} \sum_{t} T w_{k j} T l_{k k^{\prime}}{ }^{\prime j t}
\end{gathered}
$$

$$
\begin{gathered}
M i n Z_{2}=\sum_{i, j, p}\left(e i_{i j p}^{p d}+e i_{i p}^{p r o}\right) x_{i j p}+\sum_{j, k, p}\left(e i_{j k p}^{d c}+e i_{j p}^{i n}\right) u_{j k p}+\sum_{i, j, p}\left(e i_{j i p}^{i p}+e i_{i p}^{r e}\right) v_{j i p}+\sum_{j, m, p}\left(e i_{j m p}^{i d}+\right. \\
\left.e i_{m p}^{d i}\right) T_{j m p} \\
L_{k j t}=L_{k j(t-1)}+H l_{k j t}-F l_{k j t}+\sum_{k^{\prime}} T l_{k^{\prime} k j t}-\sum_{k^{\prime}} T l_{k k^{\prime} j t} \forall k, j, t \\
\sum_{L} \mathrm{a}_{\mathrm{jt}}^{\mathrm{kl}} \mathrm{x}_{\mathrm{jt}}^{\mathrm{kl}} \leq \mathrm{L}_{\mathrm{kjt}} \forall k, j, t \\
\sum_{\mathrm{k}} A_{t k j} \mathrm{~L}_{\mathrm{tkj}} \geq \sum_{\mathrm{k}} \sum_{\mathrm{L}} \mathrm{b}_{\mathrm{jlk}} \mathrm{X}_{\mathrm{jt}}^{\mathrm{LK}} \forall j, t(20) \\
\sum_{j} X_{s j t}^{L} \leq C a p_{s t}^{L} \forall L, s, t \\
\sum_{\mathrm{k}} \mathrm{X}_{\mathrm{jt}}^{\mathrm{kL}}=\sum_{\mathrm{s}} \mathrm{X}_{\mathrm{sjt}}^{\mathrm{L}} \forall \mathrm{L}, \mathrm{j}, \mathrm{t} \\
\sum_{\mathrm{k}^{\prime}} \mathrm{TL}_{\mathrm{kk}{ }^{\prime} \mathrm{jt}} \leq \mathrm{L}_{\mathrm{kj}(\mathrm{t}-1)} \forall k, j, t \\
\sum_{k^{\prime}} T L_{k k^{\prime} j t} \leq M Y_{k j t} \\
\left.\mathrm{FL}_{\mathrm{kjt}}+17\right) \\
F L_{k j t} \leq M\left(1-Y_{k j t}\right) \\
Y_{k j t} \in\{0,1\} \\
T p_{k k^{\prime}}, \forall k, k^{\prime}, j, t
\end{gathered}
$$$$
\left.e i_{m p}^{d i}\right) T_{j m p}
$$

$$
\begin{array}{r}
\sum_{k}\left(F L_{k j t}+H L_{k j t}\right) \leq \alpha_{(t-1)} \sum_{k} L_{k j(t-1)} \forall j, t \\
\mathrm{X}_{\mathrm{sjt}}^{\mathrm{L}}, \mathrm{X}_{\mathrm{jt}}^{\mathrm{lk}}, \mathrm{Y}_{\mathrm{jct}}, \mathrm{I}_{\mathrm{jt}}, \mathrm{L}_{\mathrm{kjt}}, \mathrm{Fl}_{\mathrm{kjt}}, \mathrm{Hl}_{\mathrm{kjt}}, \mathrm{Tl}_{\mathrm{kk}{ }^{\prime j t}} \geq 0
\end{array}
$$

\subsection{Model Solving}

The first part of the chromosome consist of a four dimensional matrix that show the values of $X_{j t}^{\mathrm{Lk}}$ variable. In this chromosome, the arrays of the matrix are integers in which the amount of products are determined using ordinary materials of type $\mathrm{l}$, by work labor with the skill of level $\mathrm{k}$ in the period $\mathrm{t}$ as well as in factory $\mathrm{j}$.

The second part of the chromosome determines the method of supplying primary materials for the factory via suppliers. In other words it is determined that any producer provides its primary materials of level L in any period from that producer. Since the capacity of producers is limited, this section of the chromosome is shown as numbers between zero and one that are indicators of priorities. This section of the chromosome is determined from a three dimensional matrix with dimensions (the number of the period * the number of material type * the number of producers). 
In the third part of the chromosome, it is specified that any customer provides its necessity from which producer or supplier. This section is formed from a three dimensional matrix with dimensions (number of the period * number of producers * number of customers) with arrays between zero and one. The arrays in this part like the arrays in the second part indicate priorities and according to the capacity of any of producers the demand of customers are covered according to these priorities. To understand how a chromosome works and how is decoded an example is given bellow. Consider the following problem.

Assume 3 suppliers, 2 customers, 3 producers and 1 period. Also, assume one chromosome for this problem is as follows:

Table 1 . The values of variable $X_{\mathrm{jt}}^{\mathrm{Lk}}$

\begin{tabular}{lccc}
\hline $\mathrm{J}=1, \mathrm{t}=1$ & $\mathrm{~K}_{1}$ & $\mathrm{~K}_{2}$ & $\mathrm{~K}_{3}$ \\
\hline $\mathrm{L}_{1}$ & 23 & 35 & 14 \\
$\mathrm{~L}_{2}$ & 16 & 42 & 24 \\
$\mathrm{~L}_{3}$ & 35 & 26 & 11 \\
\hline & & & \\
\hline $\mathrm{J}=2, \mathrm{t}=1$ & $\mathrm{~K}_{1}$ & $\mathrm{~K}_{2}$ & $\mathrm{~K}_{3}$ \\
\hline $\mathrm{L}_{1}$ & 26 & 25 & 5 \\
$\mathrm{~L}_{2}$ & 23 & 28 & 26 \\
$\mathrm{~L}_{3}$ & 35 & 22 & 6 \\
\hline
\end{tabular}

As shown the production value of each producer is specified. As an example the amount of product that is produces with the primary material of level $2\left(\mathrm{~L}_{2}\right)$ and the labor force with first level of skill by second producer $\left(\mathrm{j}_{2}\right)$ is equal to 21 . The other values is also determined the same. Assume the second part of the chromosome be as follows:

Table 2. Priority matrix

\begin{tabular}{rccc}
\hline $\mathrm{T}=1$ & $\mathrm{~L}_{1}$ & $\mathrm{~L}_{2}$ & $\mathrm{~L}_{3}$ \\
\hline $\mathrm{j}_{1}$ & 0.09 & 0.18 & 0.55 \\
$\mathrm{j}_{2}$ & 0.95 & 0.34 & 0.02
\end{tabular}

In this section it is determined how each primary material that is needed for producers is supplied. This is done according to the priorities. For example in the above chromosome the highest priority is related to the material $\mathrm{L}_{1}$ with producer $\mathrm{j}_{2}$ that its priority is 0.95 . From the first section of the chromosome the material type $1\left(\mathrm{~L}_{1}\right)$ needed for producer $2\left(j_{2}\right)$ is equal to $56(26+25+5)$. So, first this amount should be produced. To produce this amount we act as follows.

Assume that the parameter $\mathrm{C}_{\mathrm{ls}}$ that is the price of material type $\mathrm{L}$ from produce s be equal to:

Table 3. Purchase price of material type L from supplier s

\begin{tabular}{ccc}
\hline & $\mathrm{S}_{1}$ & $\mathrm{~S}_{2}$ \\
\hline $\mathrm{L}_{1}$ & 52 & 46 \\
$\mathrm{~L}_{2}$ & 46 & 5 \\
$\mathrm{~L}_{3}$ & 30 & 22 \\
\hline
\end{tabular}

Also, the transportation of each of the supplier to producers $\left(\mathrm{Tc}_{\mathrm{sj}}\right)$ is as follows:

Table 4. Second part of the chromosome 


\begin{tabular}{|c|c|c|}
\hline & $\mathrm{J}_{1}$ & $\mathrm{~J}_{2}$ \\
\hline $\mathrm{S}_{1}$ & 2 & 6 \\
\hline $\mathrm{S}_{2}$ & 2 & 5 \\
\hline
\end{tabular}

Now to supply 56 unit of the material type 1 for the second producer, we calculate the cost of each unit of the primary materials that includes the purchase cost and the cost of transportation for all suppliers that is as follows:

The cost of transporting $L_{1}$ from $s_{1}$ to $j_{2}=52+6=58$

The cost of transporting $L_{1}$ from $s_{2}$ to $j_{2}=46+5=51$

So, among suppliers 1 and 2, the second supplier is used for suppling 56 unit of the primary materials of type 1 and producer 2. However, if the remaining capacity of the second supplier be not sufficient for this demand, the remaining demand of the second supplier is produced from the next supplier (costly).

This procedure continues until the demand of all producers satisfies. In this section the amount of raw material supplied by each supplier $\left(\mathrm{x}_{\mathrm{sjt}}^{\mathrm{l}}\right)$ is determined.

In the third part assume that the related chromosome be as follows:

Table 5. Matrix of second part priorities

\begin{tabular}{ccl}
\hline $\mathrm{t}=1$ & $\mathrm{~J}_{1}$ & $\mathrm{~J}_{2}$ \\
\hline $\mathrm{C}_{1}$ & 0.32 & 0.44 \\
$\mathrm{C}_{2}$ & 0.92 & 0.35 \\
$\mathrm{C}_{3}$ & 0.54 & 0.18 \\
\hline
\end{tabular}

In this section each customer receive the need of his period from the producers. Customers receive their demand according to the priority and the capacity of producers. For example in the above sample, first the demand of customer 2 from producer 1 is received. To satisfy the demands of customers first the products of level 1 , then level 2 and finally level 3 was used. In the above example assume the stock of product type 1 in producer 1 is 50 units, but the demand of the second customer is 75 units. So, 50 unit of the demand of customer 2 is from the producer 1 and the remaining is get from producer 2 .

In each chromosome by having the information of these three parts of the chromosome, all variables of the problem is calculable.

\subsection{Initialization Method}

After determining a structure for displaying the solutions of the problem, the first step of the algorithm is determining the primary population of the solutions. Most population-based evolutionary meta-heuristic algorithms use a random approach for initialization. Here this approach is chosen that a random chromosome is produced for each of the population, the produced chromosome is investigated and if does not violate any of the limitations of the problem, will be confirmed and otherwise the produced chromosome will be rejected and the production of the chromosome will be repeated. This process will be repeated until the initial population will be completed.

\subsection{Evaluation of the Results}

In the next step, the produced population should be evaluated. To this regard, first the formed chromosomes should be explained via decoding and be changed to the equivalent results. As noted in the previous section, by having three parts of a chromosome all variables of the problem is calculable and so via putting these values in the cost functions, cost functions are calculable. Then, it is the time of rating results and putting them in different foreheads via being non-dominated using the method of non-dominated sorting that was explained previously. Then, crowding distance is calculated for the results via the procedure mentioned previously.

\subsection{Selection Mechanism}

To produce the population of children from parents, it is necessary to select several of the parents for applying 
the intersection and mutation operator. The selected method that is used in this algorithm is the Binary Tournament based on compaction comparison that was explained before.

In fact this method is a mechanism for implementation of two concept of non-dominated sorting and distance of the population. This method is as follows:

First select two chromosome randomly

The winner between these two chromosome that is determined as follows, is selected as the output

Which has lower Pareto Front

If the number of Pareto Fronts is equal, select one which has bigger crowd distance

The method of Pareto Front lining and exact definition of crowd distance is explained widely in section 5 .

\section{Genetic Operators}

Creation of the population of children from parents that is done to produce higher quality results from the previous generation and in fact is considered an evolutionary procedure. In genetic algorithm the evolution of population is performed through genetic operators such as crossover, mutation and elitism. But each of these operators, have various types for different issues and the performance of each of them can be different in the development of the algorithm. Now we introduce crossover and mutation operators that are used in this thesis.

\subsection{Crossover Operators}

Crossover operator is applied to transform similar characters from parents to children. In fact each children should inherit some characters form one parent and the remaining from the other. If an operator do not guarantee such conditions then it is not named crossover operator but is called mutation operator. Usually crossover operator get two parents and produce maximum two children. Thus, for performing the crossover first the parents (chromosomes that crossover operator should be applied on them) should be selected. The method of selecting parents in this research is Toromont method as mentioned. The method of applying crossover operator on the selected parents is such that for any part of the chromosome a help matrix with the same dimension is stablished that its arrays are formed with binary numbers. The method of children formation is as the following figure shows:

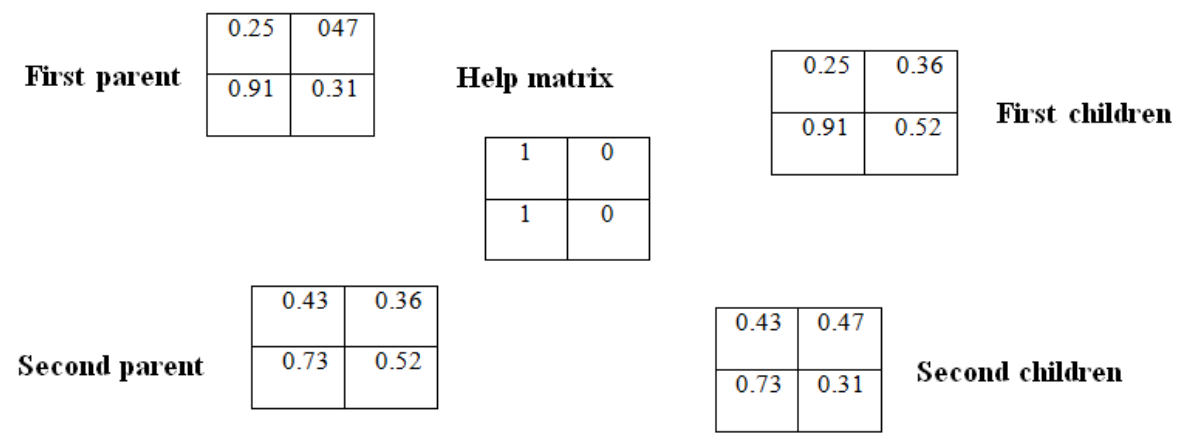

Figure 6. Crossover operator

If the produced children contradict the limitation of the problem we put it aside and repeat the operator.

\subsection{Mutation Operator}

Mutation operator is used for creation dispersion in the results and better search of results. Since there is no goal orientation in the operator, the way of executing it is such that the chromosome is changed randomly. For the mutation operator in the introduced algorithm we have produced new chromosome and replaced it with the previous chromosome. In other words the new chromosome is produced and if possible is replaced with the previous chromosome.

\subsection{Elitism}

In the introduced algorithm some of the population directly transforms from any generation to the next generation. These are selected from the best results of each generation. 


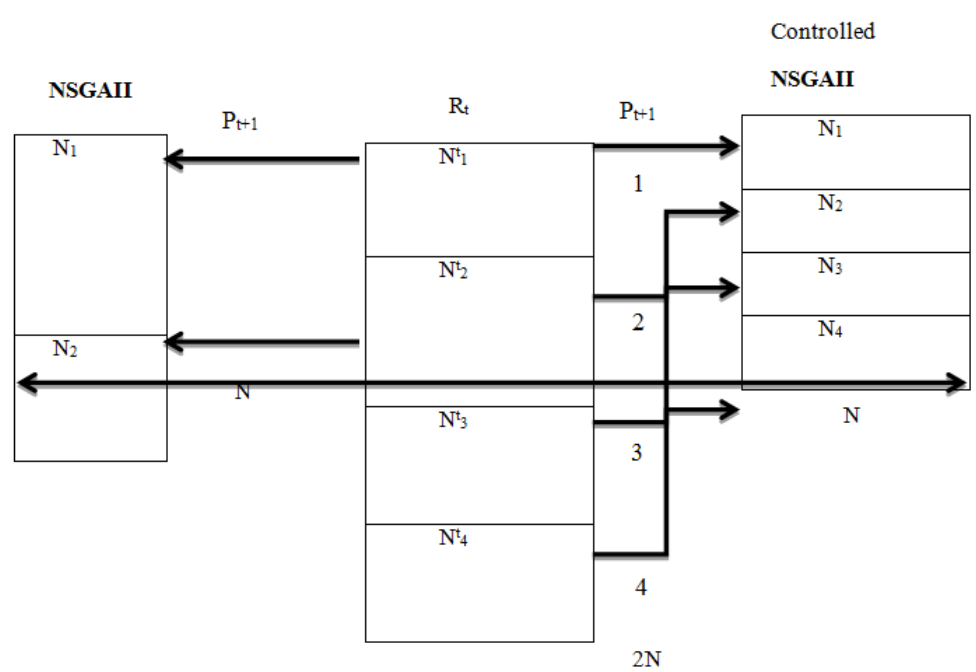

Figure 1. Elitism

\subsection{Algorithm Iteration}

After random production of the initial population of parents and evaluation of them according to the selection method and genetic operators that was explained, the population of children are produced equal to the parents. Combining these two sets, next generation produces according to the structure that introduced previously. So, a repeating of algorithm is done and this process is repeated to reach the final condition of the algorithm. Finally, first Pareto Front of the last generation that are the non-dominated of the set, are evoked as the algorithm's output.

\subsection{Algorithm's Stop Condition}

Algorithm's Stop condition is in fact a criteria that determines when the repetition of the loop stops and it can be distinct according to designer's view. The most usual condition is the numbers of repeating algorithm that for example the algorithm stops after $\mathrm{K}$ iteration. In this thesis we have selected the specific number of iteration as the stop condition.

\subsection{Explaining the Structure of the Used(NRGA)(Note 1) Algorithm in this Research}

NRGA algorithm is similar to NSGAII algorithm structurally. The only difference of this algorithm with the NSGAII algorithm is in the selection strategy, the population sorting section and selection for the next generation. In other words In NRGA algorithm the selection of parents instead of the binary crowd method is via the Roulette method which was explained in the previous chapter in detail.

\subsection{Evaluation of the-Objective Meta-Heuristic Algorithm}

In this section to evaluate the efficiency of the proposed two-objective algorithm, we use the criteria of evaluation of the efficiency of multi-objective problems. The criteria of the efficiency of multi-objective problem was studied separately in the second chapter because of its high importance. In this study we use the following four measurement criteria.

Q: Quality

NPS: Number of Pareto Solutions

RAS: rate of achievement to two objectives simultaneously

DM: Diversification Matrix

After coding the problem to efficiency and performance evaluation of the NSGAII algorithm against NRGA algorithm, we solve and compare them for 20 different typical problems. To obtain reliable results we run each sample 3 times and similar to the previous procedure we measure the normalized mean values of different criteria. Sample results for different combination of S, J, C and T for both algorithms are summarized in table 6 according to the criteria which was referred to above and were explained completely in the second chapter. 
Table 6. comparison of the NRGA AND NSGAII algorithms

\begin{tabular}{|c|c|c|c|c|c|c|c|c|c|c|c|}
\hline \multicolumn{12}{|c|}{ Normalized values of NRGA Normalized values of NSGAII } \\
\hline No. & $\mathrm{s}$ & $\mathrm{j}$ & $\mathrm{c}$ & $\mathrm{T}$ & NPS & RAS & $\mathrm{DM}$ & & NPS & RAS & $\mathrm{DM}$ \\
\hline 1 & 2 & 2 & 3 & 2 & 15.33 & 672.22 & 2.01 & & 19.00 & 674.59 & 2.19 \\
\hline 2 & 5 & 3 & 5 & 2 & 22.33 & 702.48 & 2.69 & & 23.00 & 709.8 & 2.95 \\
\hline 3 & 5 & 4 & 7 & 2 & 20.66 & 740.27 & 3.46 & & 20.00 & 726.31 & 3.88 \\
\hline 4 & 5 & 5 & 9 & 3 & 19.66 & 730.60 & 5.13 & & 17.33 & 717.00 & 4.79 \\
\hline 5 & 10 & 7 & 11 & 3 & 18.00 & 748.89 & 6.42 & & 18.66 & 728.27 & 6.45 \\
\hline 6 & 10 & 8 & 13 & 3 & 19.66 & 745.79 & 8.09 & & 19.66 & 703.77 & 8.12 \\
\hline 7 & 10 & 9 & 15 & 4 & 19.00 & 733.39 & 10.36 & & 22.33 & 722.90 & 10.32 \\
\hline 8 & 15 & 11 & 17 & 4 & 22.33 & 740.19 & 12.31 & & 19.33 & 721.86 & 13.49 \\
\hline 9 & 15 & 12 & 19 & 4 & 19.66 & 743.90 & 14.33 & & 19.00 & 725.67 & 14.55 \\
\hline 10 & 15 & 13 & 21 & 5 & 18.33 & 745.79 & 20.22 & $\mathrm{Z}$ & 20.33 & 725.27 & 20.58 \\
\hline 11 & 20 & 15 & 23 & 5 & 18.00 & 727.53 & 20.88 & & 19.00 & 728.19 & 20.77 \\
\hline 12 & 20 & 16 & 25 & 5 & 21.00 & 733.41 & 21.85 & & 22.66 & 731.28 & 22.42 \\
\hline 13 & 20 & 17 & 27 & 6 & 20.33 & 732.21 & 29.96 & & 22.33 & 727.09 & 28.99 \\
\hline 14 & 25 & 19 & 29 & 6 & 18.66 & 728.04 & 31.90 & & 18.66 & 720.85 & 32.53 \\
\hline 15 & 25 & 20 & 31 & 6 & 17.00 & 742.72 & 33.86 & & 20.00 & 729.79 & 35.55 \\
\hline 16 & 25 & 21 & 33 & 7 & 14.33 & 748.76 & 39.60 & & 18.33 & 721.30 & 39.96 \\
\hline 17 & 30 & 23 & 35 & 7 & 17.33 & 711.68 & 44.37 & & 20.66 & 720.37 & 44.85 \\
\hline 18 & 30 & 24 & 37 & 7 & 21.33 & 732.40 & 45.86 & & 21.66 & 713.21 & 44.69 \\
\hline 19 & 30 & 25 & 40 & 8 & 19.66 & 720.07 & 52.28 & & 21.00 & 701.18 & 52.69 \\
\hline 20 & 35 & 30 & 45 & 8 & 20.00 & 712.54 & 62.95 & & 20.33 & 710.98 & 65.72 \\
\hline \multicolumn{5}{|c|}{ AVRAGE } & 19.13 & 729.698 & 23.4265 & & 20.1635 & 717.984 & 23.7745 \\
\hline
\end{tabular}

\section{Conclusion}

In this study, for the problem of integrated programming of purchase-production-customer in a supply chain network, a certain and multi-objective model is developed with two contradictory goals including 1minimization of costs and 2- minimization of environmental pollutants. Moreover, the proposed model has linked product quality not only to last ring attached to customer that is manufacturer, but also it has linked it to raw materials shipped to manufacturer and involvement of labors with different skills with the materials. The presented model was firstly a nonlinear model that is changed into a linear programming method using research techniques during the operations and has been validated with a problem in small dimensions using Lingo Software. To solve the problem, fuzzy goal programming method is applied.

\section{References}

Beamon, B. M. (1998). Supply chain design and analysis: model and methods. International Journal of Production Economics, 55, 194-281.

Chen, I. J., \& Paulraj, A. (2004). Understanding supply chain management: Critical research and theoretical framework. International Journal of Production Research, 42(1), 131-163.

Donald, C., Waters, J. (2003). Global Logistics and Distribution Planning: Strategies for management, kogan page.

Dullaert, W., Braysy, O., Goetschalckx, M., \& Rua, B. (2007). supply chain (re) design: Support for managerial and policy. Decisions. Euoropean Journal of Transport and Infrastructure Research, 7, 73-91.

Feredendall, L. D., \& Hill, E. (2000). Basics of supply chain management", st. Lucie press/APICS series on resource management, 2000.

Fung, R.Y. K., \& Chen, T. (2004). A multi agent supply chain planning and coordination Architecture. The International Journal of Advanced Manufacturing Technology, 39(5-6), 612-622.

Handfield, R. B., \& Nichols, E. L. (1999). Introduction to supply chain management, prentice Hall, New Jersey.

Jamshidi, R., FatemiGhomi, S. M. T. et al. (2012). Multi-objective green supply chain optimization with a new hybrid memetic algorithm using the Taguchi method. ScientiaIranica, 19(6), 1876-1886.

Lambert, D. M., \& Cooper, M. C. (1998). Supply chain management: Implementation Issues and Research opportunities. International Journal of Logistics management, 92, 1-18. 
Lee, H. L., \& Billington, C. (1992). Management supply chain inventory: Pitfalls and opportunities. Sloan Management Review Spring, 33(3), 65-73.

Manzini, R., Gamberi, M., Gebennini, E., \& Regattieri, A. (2008). An integrated approach to the design and management of a supply chain system. International Journal of Advanced Manufacturing Technology, 37, 625-640.

Min, H., \& Zhoub, G. (2002). supply chain modeling: past, present and future. Computers Industrial Engineering, 43, 231-249.

Paksoy, T., \& Pehlivan, N. Y. et al. (2012). Fuzzy Multi-Objective Optimization of a Green Supply Chain Network with Risk Management that Includes Environmental Hazards. Human and Ecological Risk Assessment: An International Journal, 18(5), 1120-1151.

Srinivas, C., \& Rao, C. S. P. (2010). Optimization of supply chains for single-vendor-multi buyer Consignment stock policy with genetic algorithm. International Journal, Advanced Manufacturing Technology, 48(1-4), 407-420.

Vaziri, S., \& Shojaei, M. (2011). Evaluation of The commercial Bacillus thuringiensis (BT) products. Journal of Innovative Research in Engineering Sciences, 3(1), 21-25.

\section{Note}

Note 1. Non-dominated ranked genetic algorithm

\section{Copyrights}

Copyright for this article is retained by the author(s), with first publication rights granted to the journal.

This is an open-access article distributed under the terms and conditions of the Creative Commons Attribution license (http://creativecommons.org/licenses/by/4.0/). 